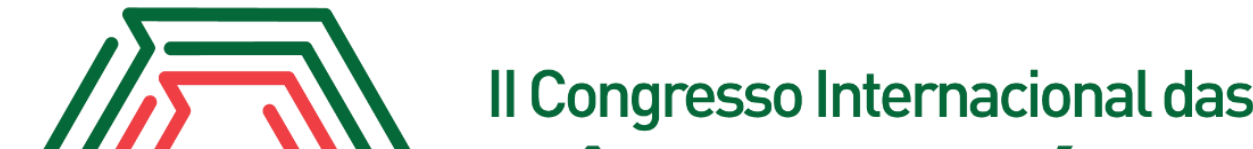 Ciências Agrárias COINTER - PDVAgro 2017
}

\section{A INCLUSÃO DE SURDOS NO ENSINO AGRÍCOLA: UM DESAFIO DO IFPE CAMPUS VITÓRIA DE SANTO ANTÃO}

\author{
Apresentação: Pôster \\ Juan Abraão Medeiros da Silva'; Tiago Edvaldo Santos Silva ${ }^{2}$; Elisangela de Freitas \\ Mariano $^{3}$; Rosicleide da Silva Santos ${ }^{4}$ Manuela Maria Santos e Silva ${ }^{5}$
}

\section{Introdução}

A educação, uma das necessidades básicas da humanidade, ainda é negada a determinados seguimentos da sociedade (Camolesi, 2004). Dentre esses seguimentos estão os mais de 12 milhões de homens, mulheres e crianças brasileiras com deficiência (IBGE, 2015). Afim de prover condições de acesso aos direitos fundamentais a esse público, no Brasil foram criadas leis, políticas e programas, muitos deles específicos a determinadas deficiências.

A trajetória do ensino agrícola no Brasil inicia em 1907, a partir da criação da Escola Superior de Agricultura em Socorro em Jaboatão dos Guararapes no estado de Pernambuco. Ao longo dos anos foram criados os centros de educação superior, médio ou teórico prático, escolas especiais de agricultura, escolas domésticas agrícolas e cursos conexos com o ensino agrícola (LIMA, 2014). No período da ditatura, o ensino agrícola passar a ter uma dimensão tecnicista, o processo educativo é compreendido como instrumento de capacitação para inserção do povo do campo na lógica da revolução verde (SILVA, 2006). As escolas agrícolas atuais, ainda em constantes transformações e continua busca por uma educação dialógica e inclusiva, são fruto desse processo.

Hoje, dentro de um contexto que não deve permitir mais a confusão entre educação, no seu sentido mais amplo, e treinamento para o mercado, existem instituições responsáveis pelo Ensino Agrícola, a exemplo do IFPE, guiadas por princípios democráticos, que asseguram condições de permanência e sucesso escolar, bem como justiça social, educação e trabalho: inclusão, diversidade e igualdade (IFPE, 2017). É usufruindo desse direito historicamente constituído que estudantes surdos

\footnotetext{
${ }^{1}$ Agropecuária, Instituto Federal de Educação, Ciência e Tecnologia de Pernambuco Campus Vitória de Santo Antão, eujuanabraao123@gmail.com

${ }^{2}$ Agronomia, Instituto Federal de Educação, Ciência e Tecnologia de Pernambuco Campus Vitória de Santo Antão, tiagoedvaldo@hotmail.com

${ }^{3}$ Mestrado em Ciências Agrárias, Universidade Federal da Paraíba, elisangela.freitas.mariano@gmail.com;

${ }^{4}$ Licenciatura em Química, Instituto Federal de Educação, Ciência e Tecnologia de Pernambuco Campus Vitória de Santo Antão, romadamesantos@gmail.com;

${ }^{5}$ Agronomia, Instituto Federal de Educação, Ciência e Tecnologia de Pernambuco Campus Vitória de Santo Antão, manuelaifpe@gmail.com.
} 
tem ingressado no IFPE a fim de se profissionalizarem em cursos técnicos agrícolas.

Diante disso, objetiva-se com esse trabalho analisar os desafios que o Instituto Federal de Educação, Ciência e Tecnologia de Pernambuco campus Vitória de Santo Antão vivencia com a inclusão de pessoas surdas nos cursos de formação Agrícola.

\section{Fundamentação Teórica}

A Constituição Federal representou a liberdade para o povo brasileiro e orientou os caminhos para a construção de uma sociedade justa e democrática. Nesse novo cenário, a educação é reconstruída. Assim, um dos seus princípios refere-se a "igualdade de condições para o acesso e permanência na escola", bem como, "a garantia da atendimento educacional especializado aos portadores de deficiência, preferencialmente na rede regular de ensino" (BRASIL, 1988). Esse marco legal possibilitou a criação de novas leis e resoluções numa tentativa de garantir igualdade e a equidade para acesso à educação.

Para as pessoas com deficiência auditiva a criação da Língua Brasileira de Sinais, Lei No 10.436, de 24 de abril de 2002 representou um avanço. No entanto, de acordo com Monteiro (2006), os movimentos sociais e políticos Surdos organizados pelas associações de Surdos, estão em continua luta pelo estabelecimento de normas e regras de funcionamento que regularizem e valorizem as associações de Surdos, bem como, possibilidades no mundo do trabalho.

De acordo com o IBGE, considera-se pessoa com deficiência auditiva aquela que apresente surdez nos dois ouvidos, surdez em um ouvido e audição reduzida no outro, ou ainda audição reduzida de ambos os ouvidos. Uma pesquisa realizada por esse órgão apontou que 1,1\%, da população nacional, aproximadamente 2211359,854 de pessoas, possuía deficiência auditiva.

\section{Metodologia}

Este estudo de caso foi desenvolvido no Instituto Federal de Educação, Ciência e Tecnologia de Pernambuco Campus Vitória de Santo Antão, a partir de questionários aplicados aos dois estudantes surdos da Instituição, trinta e três colegas ouvintes de sala, cinco técnicos administrativos de setores que lidam diretamente com estudantes e quatro professores.

As questões abordadas nos questionários para os estudantes surdos versaram sobre a regularidade do atendimento por interprete de libras, sobre o domínio dos sinais de Libras específicos do curso profissionalizante dos estudantes surdos, se já se sentiram prejudicados por falta de condições de inclusão, sobre a percepção deles acerca de atitudes diferenciadas dos professores e 
técnicos administrativos no atendimento a eles, sobre os desafios de se estudar no IFPE, enquanto pessoa surda e quais sugestões de melhorias que eles teriam.

Para os colegas ouvintes, técnicos administrativos e professores as perguntam tratavam da integração com os estudantes surdos, do nível de entendimento de Libras, a integração com os colegas surdos por meio dos interpretes, se receberam algum curso de formação para lidar com os estudantes surdos, a partir da chegada deles no IFPE.

\section{Resultados e Discussões}

Como pode-se ver nas tabelas 1 e 2, o nível de integração dos estudantes surdos com os servidores da Instituição ainda é muito comprometido, quando comparado a integração com os estudantes ouvintes. Uma característica do ouvintismo (PERLIN, 2011), que encara o ouvinte como alguém superior, e, para que os surdos tivessem o nível de integração com os servidores eles precisariam ser ouvintes.

Vê-se que profissional de interpretação da Libras cumpre um papel fundamental em facilitar essa relação, por meio da comunicação dos surdos com os ouvintes, como pode-se ver nas tabelas 1 e 2. Porém, não resolve toda a questão da inclusão de pessoas surdas. E a Instituição não ofereceu curso de formação para nenhum dos servidores, afim de melhor capacita-los para receber os estudantes surdos que passavam a fazer parte da comunidade escolar.

Tabela 1: Dados referentes aos questionários aplicados aos Técnicos Administrativos.

\section{TÉCNICOS ADMINISTRATIVOS}

Comparando sua relação com os estudantes ouvintes, quanto você atribui a seu nível de integração com os estudantes surdos dessa instituição, numa escala de 0 a 10 ?

De 0 a 10, qual seu nível de entendimento da Língua Brasileira de Sinais LIBRAS?

Você adota alguma atitude diferenciada em seus atendimentos, afim de interagir melhor com os estudantes surdos?

As interpretes de LIBRAS contemplam sua necessidade de integração com os estudantes surdos durante seus atendimentos?

A partir da chegada dos estudantes surdos, você recebeu alguma formação oferecida pelo IFPE na área de inclusão de pessoas surdas na formação agrícola profissionalizante?

Média: 2,8

Quando perguntados se procuram alguma atitude diferenciada em busca de melhorar o atendimento dos estudantes surdos, $80 \%$ dos servidores afirmaram realizar tal esforço. No entanto, o nível de entendimento de Libras é baixíssimo. O que inviabiliza a comunicação com os estudantes surdos. 
Tabela 2: Dados referentes aos questionários aplicados aos Professores.

\section{PROFESSORES}

Comparando sua relação com os estudantes ouvintes, quanto você atribui a seu nível de integração com os estudantes surdos dessa instituição, numa escala de 0 a 10 ?

De 0 a 10, qual seu nível de entendimento da Língua Brasileira de Sinais LIBRAS?

Você adota alguma atitude diferenciada em suas aulas, afim de incluir os estudantes surdos?

As interpretes de LIBRAS contemplam sua necessidade de integração com os estudantes surdos durante as aulas?

A partir da chegada dos estudantes surdos, você recebeu alguma formação oferecida pelo IFPE na área de inclusão de pessoas surdas na formação agrícola profissionalizante?

Os dados trazidos pelos estudantes ouvintes que são colegas dos surdos, também revelam que possuem dificuldades de integração com os estudantes surdos, o que muito se deve ao baixo nível de entendimento da Libras. E mesmo com o interprete em sala de aula, os colegas ouvintes acreditam que os estudantes surdos em torno de $64 \%$ dos conteúdos trabalhados em sala de aula.

Caminhando nesse sentido, um estudo realizado por Mallmann (2014), em instituições do Ensino Médio e Ensino e Profissionalizante, buscando refletir sobre a percepção dos docentes em relação a inclusão do estudante surdo, permitiu concluir que a inclusão dos surdos nas escolas regulares é garantida pela legislação e dispõe de um aparato teórico consistente, no entanto, no campo prático ainda são observadas fragilidades que dificultam o efetivo aprendizado do aluno surdo.

Tabela 3: Dados referentes aos questionários aplicados aos colegas ouvintes

\begin{tabular}{|l|c|c|}
\hline \multicolumn{2}{|c|}{ COLEGAS } \\
\hline $\begin{array}{l}\text { Comparando sua relação com os estudantes ouvintes, quanto você atribui a seu } \\
\text { nível de integração com os estudantes surdos dessa instituição, numa escala de 0 } \\
\text { a 10? }\end{array}$ \\
\hline $\begin{array}{l}\text { De 0 a 10, qual seu nível de entendimento da Língua Brasileira de Sinais - } \\
\text { LIBRAS? }\end{array}$ \\
\hline $\begin{array}{l}\text { Você percebe alguma atitude diferenciada dos professores em suas aulas, afim de } \\
\text { incluir os estudantes surdos? }\end{array}$ & $\begin{array}{c}\text { SIM: } \\
78,7 \%\end{array}$ & $\begin{array}{c}\text { Não: } \\
21,3 \%\end{array}$ \\
\hline $\begin{array}{l}\text { As interpretes de LIBRAS contemplam sua necessidade de integração com } \\
\text { seu/sua colega surdo/a durante as aulas? }\end{array}$ & $\begin{array}{c}\text { SIM: } \\
84,8 \%\end{array}$ & $\begin{array}{c}\text { Não: } \\
15,2 \%\end{array}$ \\
\hline $\begin{array}{l}\text { De } 0 \text { a } 10 \text { quanto você acredita que seus colegas surdos aproveitam dos } \\
\text { conteúdos trabalhados em sala de aula? }\end{array}$ & 6,4 \\
\hline
\end{tabular}

Estes fatos corroboram com os trabalhos de Santos Filho (2015), ao analisar a escolarização de estudantes do surdos do Ensino Médio (EM) em uma escola pública do município de Natal - RN, percebeu que os estudantes surdos tiveram acesso e a permanência no EM garantida, no entanto, estes 
relataram poucas participações nas atividades realizadas em sala de aula.

Os apresentados pelos próprios surdos permitem ainda observar que não há regularidade no atendimento por interpretes, frisam a importância e necessidade desse profissional e afirmam já haverem ter sido prejudicados academicamente por não ter suas necessidades especiais atendidas.

\section{Conclusões}

Os estudantes surdos que adentram ao IFPE campus Vitória de Santo Antão, uma instituição de vocação predominantemente agrícola, tem limitações na integração com os servidores administrativos, professores e colegas, sobretudo pelo baixo nível de entendimento destes da Libras. A casa tem recebido estudantes surdos, porém, não apresenta condições adequadas para propiciar o desenvolvimento integral desses estudantes.

\section{.Referências}

BRASIL. Lei no 10.436, de 24 de abril de 2002. Dispõe sobre a Língua Brasileira de Sinais - Libras e dá outras providências. Disponível em: < http://www.planalto.gov.br/ccivil_03/leis/2002/L10436.htm>. Acesso em: 13 de outubro de 2017.

BRASIL. Pesquisa nacional de saúde - IBGE. Rio de Janeiro: IBGE, 2015. 92 p.

Brasil, Projeto Político Pedagógico Institucional do IFPE: Recife, 2017. Disponível em

CAMOLESI, Marcos Roberto Haddad. O direito à inclusão da pessoa portadora de deficiência à luz da legislação brasileira. Jus NAvigandi, Teresina, a. 8, n.242, 6 marc. 2004. Disponível em http://www1.jus.com.br/doutrina/texto.asp?id=4928. Acesso em: 05 de outubro de 2017, p. 1.

SILVA, M. S. Da raiz à flor: produção pedagógica dos movimentos sociais e a escola do campo. Educação do campo e pesquisa: questões para reflexão. Brasília: Ministério do Desenvolvimento Agrário, p. 60-79, 2006.

LIMA, J. R. T. Caminhos percorridos. Caminhos a percorrer. 50 anos do Departamento de Educação da UFRPE. p. 1 - 12, 2014.

MALLMANN, Fagner Michel et al. A inclusão do aluno surdo no Ensino Médio e ensino profissionalizante: um olhar para os discursos dos educadores. Rev. bras. educ. espec, v. 20, n. 1, p. 131-146, 2014.

MONTEIRO, M. S. História dos movimentos dos surdos e o reconhecimento da LIBRAS no Brasil. ETD-Educação Temática Digital, v. 7, n. 2, p. 295-305, 2006.

SANTOS FILHO, P. L. Escolarização de surdos no ensino médio em Natal/RN: vendo e ouvindo vozes. 2015. Dissertação de Mestrado. Universidade Federal do Rio Grande do Norte. 2015. 137 f. 